\title{
Plastic Folding of Bar Stocks of Round and Barrel-Shaped Sections
}

\author{
O.S. Zhelezkov ${ }^{1, a}$, A.A. Laktyushin ${ }^{1,2, b}$, R.R. Dema ${ }^{1, c^{*}}$ and B.B. Makarov ${ }^{1, d}$ \\ ${ }^{1}$ Nosov Magnitogorsk State Technical University, 455000, Magnitogorsk, ave. Lenin, 38, Russia \\ 2 Holding ARS LLC, 127254, Moscow, Ogorodny proezd 5, building 6, Russia \\ aferumoff@mail.ru, b Lotos77707@inbox.ru, cdemarr78@mail.ru, dlatolegraf@list.ru
}

Keywords: Plastic Bending, Plastic Folding, Bar Stock, Round and Barrel-Shaped Section, Bending Angle, Tool Movement, Finite Element Modeling, Deformation Force

\begin{abstract}
Research has been carried out on the process of plastic folding of bar stocks with round and barrel-shaped cross-sections. The dependence of the movement of the movable tool on the bending angle has been established. The force parameters of the deformation process and the stress-strain state in the bending workpiece are determined based on the results of finite element modeling of plastic bending.
\end{abstract}

\section{Introduction}

Rod products formed using plastic bending operations are widely used in various industries, railway transport, construction, etc. In particular, spring clips are widely used in modern railway track structures $[1,2]$, bent reinforcing wire in the form of clamps is used in reinforced concrete structures [3], and bent welded links are used in lifting devices for various purposes [4].

Either standard presses with special technological equipment in the form of bending dies or special bending machines and mechanisms are used to implement the bending processes.

Plastic bending is a shaping operation in which there is a change in the curvature of the bar axis of the workpiece [5,6]. In the process of bending, only a part of the workpiece in the form of a deformation zone is subject to plastic deformation. The rest of the bar of the workpiece either does not deform or deform elastically. Uneven stresses and deformations occur along the section of the deformation zone. Linear deformation along the workpiece axis is practically absent.

\section{Materials and Methods}

Folding finds wide application among the variety of plastic bending methods [7-10]. In fig. 1 shows a diagram of plastic folding of a bar stock. The original workpiece 1 with a section radius $r$ is fixed on the supporting surface of the stationary tool 2, the working cylindrical surface of which has a radius $R_{1}$. Deformation of the workpiece is carried out by a movable working tool 3, the working surface of which is made in the form of a cylinder with a radius of $R_{2}$. The original length of the deformable section of the workpiece is $l$. When moving the working tool by the value $h$, the workpiece is bent through an angle $\alpha$.

Based on the analysis of the geometric relationships of the sizes and parameters of the bending process, the dependence of the movement of the working tool $\mathrm{h}$ on the angle $\alpha$ was established

$$
h=\left[l-\left(R_{1}+r\right) \cdot \operatorname{tg}(\alpha / 2)\right] \operatorname{tg} \alpha-\left(R_{2}+r\right)(1 / \cos \alpha-1),
$$

where $l$ is the initial length of the deformable section of the workpiece;

$R_{1}$ is the radius of the bearing surface of the stationary tool;

$R_{2}$ is the radius of the working surface of the movable tool; 
$r$ is the radius of the cross section of the original workpiece.

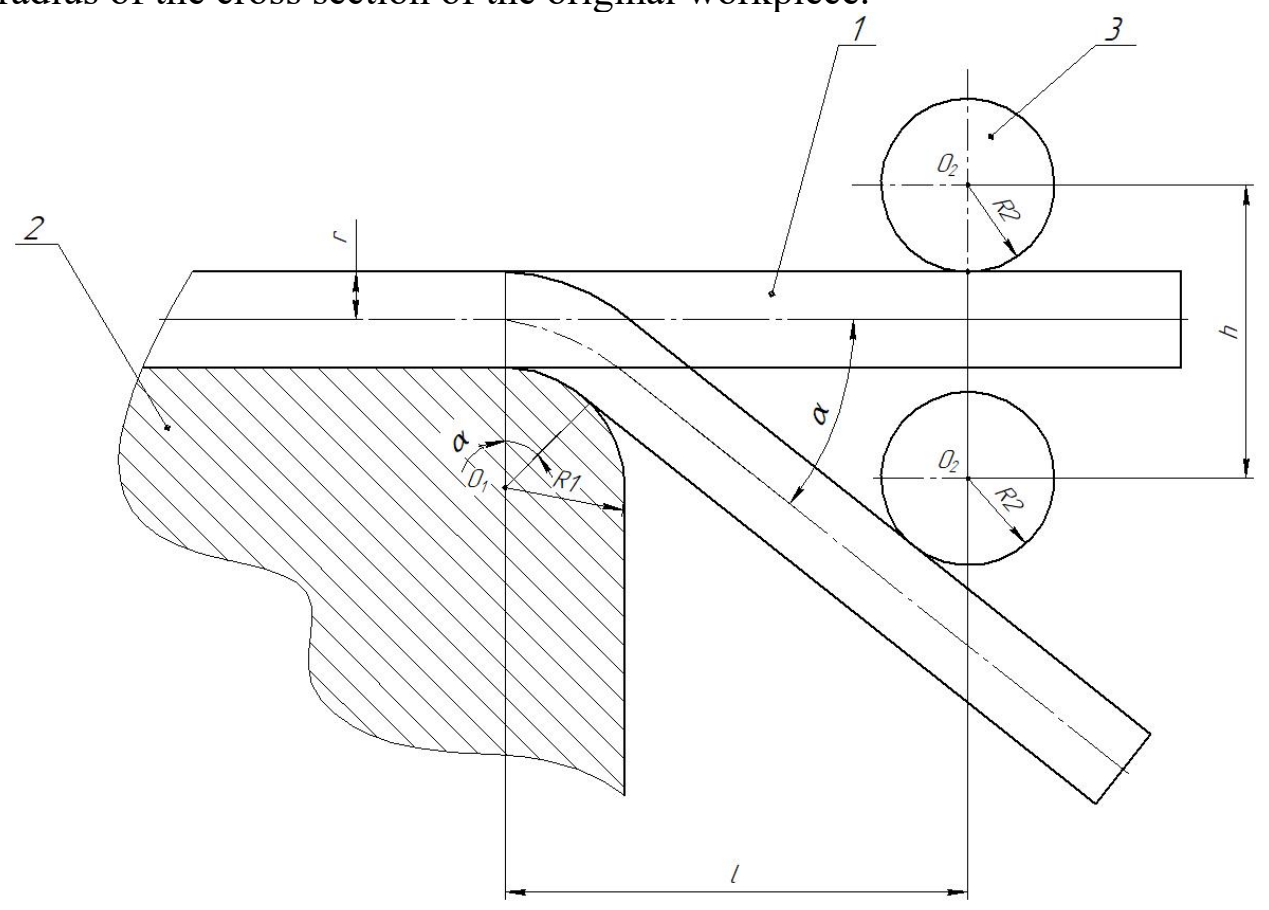

Fig. 1. Folding scheme

Computer modeling of the process of folding of bar stocks with round and barrel-shaped sections using the finite element method based on the widely used DEFORM-3D software package [11-16] has been performed. Fig. 2 shows the cross-sections of bent workpieces. The main dimensions of the sections are $d=17 \mathrm{~mm} ; \mathrm{h}=13 \mathrm{~mm} ; \mathrm{a}=12 \mathrm{~mm} ; \mathrm{b}=21 \mathrm{~mm}$. The cross-sectional areas are close in size for given dimensions. The moment of inertia of the area relative to the $x$ axis is minimal, and relative to the $y$-axis is maximum for a barrel-shaped section.

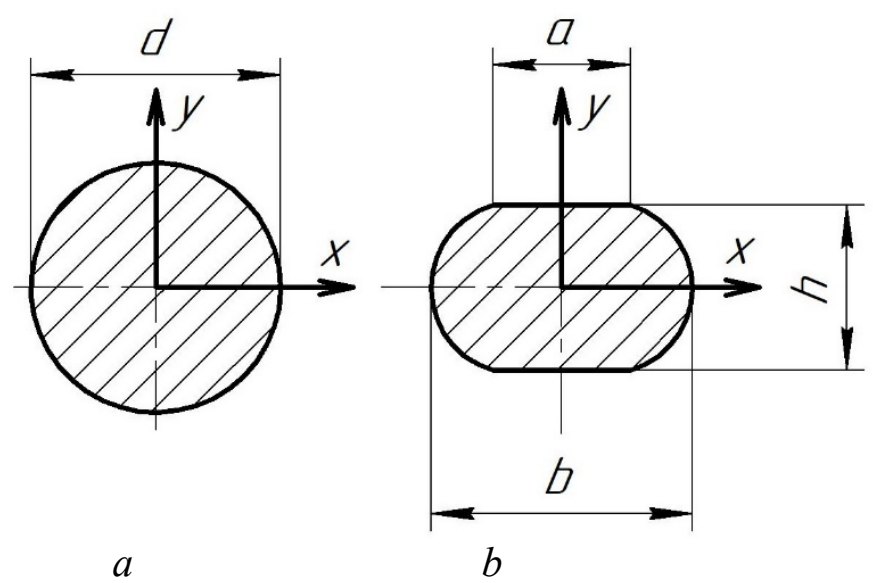

Fig. 2. Cross-sections of bar stocks:

$a$-round section; $b$-barrel-shaped section. 
The workpiece material is steel 40S2A (GOST 14959-2016), which is used in the manufacture of spring clips for fastening rails. The mechanical properties and the hardening curve of 40S2A steel were determined from the results of tensile tests [3].

\section{Results and Discussion}

Fig. 3 shows the position of the workpiece and the tool at the intermediate stage of the cantilever bending process and the stress intensity distribution field $\sigma_{i}$ in the deformation zone.
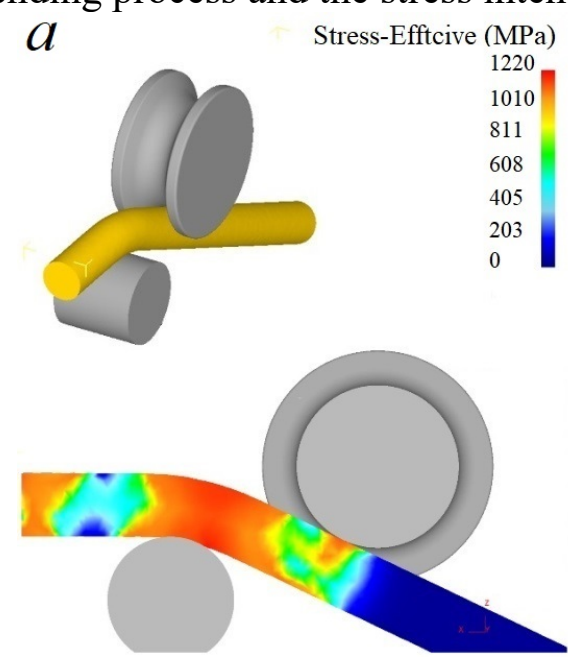

Fig. 3. The position of the workpiece and the tool at the intermediate stage of deformation and the stress intensity distribution field $\sigma_{i}$ in the plastic zones:

$a$-round section; $b$ - barrel-shaped section in bending about the $x$-axis;

$c$ - barrel-shaped in bending about the y-axis

The graphs of the dependence of the bending force $P$ on the movement of the movable tool $h$ were built, which are shown in Fig. 4 based on the results of the calculations. Curve $a$ is bending of a round section, curve $b$ is bending of a barrel-shaped section about the $x$-axis, curve $c$ is bending of a barrel-shaped section about the $y$-axis.

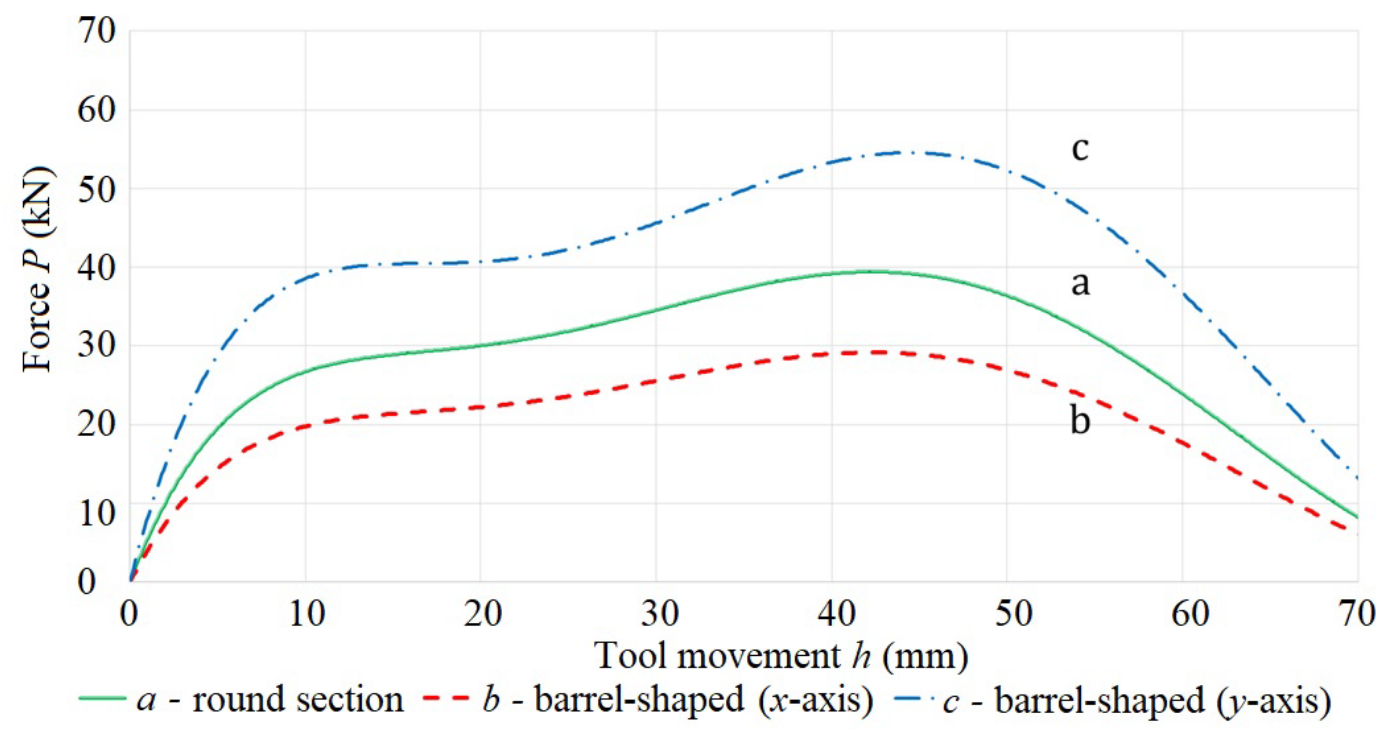

Fig. 4. Change in the deformation force $P$ when moving the movable tool $h$ :

$a$-round section; $b$-barrel-shaped about the $x$-axis; $c$-barrel-shaped about the $y$-axis 
The polynomial of the 6th degree was used to describe the nature of the change in deformation forces depending on the movement of the movable tool.

$$
P=a_{1} h^{6}+a_{2} h^{5}+a_{3} h^{4}+a_{4} h^{3}+a_{5} h^{2}+a_{6} h .
$$

Equation (2) quite accurately describes the nature of the change in the bending force $P$ from the movement of the movable tool $h$, since the coefficients of determination have a high value $\left(\mathrm{R}^{2}=\right.$ $0.995 \ldots 0.998)$. The values of the coefficients of the polynomial (2) are presented in the table 1 .

Table 1. Coefficients of equation (2)

\begin{tabular}{|c|c|c|c|c|c|c|}
\hline \multirow{2}{*}{ Section } & \multicolumn{6}{|c|}{ Coefficient values } \\
\cline { 2 - 7 } & $a_{1}$ & $a_{2}$ & $a_{3}$ & $a_{4}$ & $a_{5}$ & $a_{6}$ \\
\hline Round & $-10^{-8}$ & $3 \cdot 10^{-6}$ & $-0,0004$ & 0,0187 & $-0,4692$ & 5,8317 \\
\hline $\begin{array}{c}\text { Barrel- } \\
\text { shaped } \\
(x \text {-axis })\end{array}$ & $-10^{-8}$ & $4 \cdot 10^{-6}$ & $-0,0005$ & 0,0277 & $-0,7138$ & 8,699 \\
\hline $\begin{array}{c}\text { Barrel- } \\
\text { shaped } \\
(y \text {-axis })\end{array}$ & $-8 \cdot 10^{-9}$ & $2 \cdot 10^{-6}$ & $-0,0003$ & 0,0138 & $-0,3472$ & 4,3154 \\
\hline
\end{tabular}

\section{Conclusion}

Based on the research results, the following conclusions can be drawn.

1. Based on the results of the analysis of the geometric relationships of the sizes and parameters of the bending process, the dependence of the movement of the working tool $h$ on the bending angle $\alpha$ was established.

2. Finite element modeling of the process of plastic folding of bar stocks with round and barrelshaped sections has been carried out. It was found that when bending the barrel-shaped section relative to the $x$-axis with a minimum moment of inertia, the maximum bending force is 2.4 times less than when bending the round section and 1.88 times less than when bending a barrel-shaped section relative to the $y$-axis with a maximum moment of inertia.

3. The obtained research results are recommended to be used when choosing equipment for plastic bending of rod products, when designing a bending tool and assessing its service life.

\section{Acknowledgments}

This work is carried out within a framework of the government order (No. FZRU-2020-0011) of the Ministry of Science and Higher Education of the Russian Federation.

\section{References}

[1] I.N. Eisenmann, Improvement of the upper structure of the railway track, ZHeleznye dorogi mira, 12 (1997) 61-65.

[2] V.M. Fedin, A.I Borts., V.V. Kuznetsov et al., Production technology of elastic terminals for rail fasteners ZhBR-65: ways of improvement, Vesti VNIIZhT, 5 (2005) 21-27.

[3] A.N. Malakhova, Reinforcement of reinforced concrete structures, Stroitel'stvo, Moscow, 2014. 
[4] B.P. Dodonov, V.A. Lifanov, Hoisting and transport devices, Mashinostroenie, Moscow, 1990.

[5] M.I. Lysov, Theory and calculation of the processes of manufacturing parts by bending methods, Mashinostroenie, Moscow, 1971.

[6] S.I. Vdovin, N.V. Petrov, Engineering calculations of bending operations, Kuznechnoshtampovochnoe proizvodstvo. Obrabotka materialov davleniem, 12 (2004) 26-28.

[7] V. Kobelev, Elastoplastic Stress Analysis and Residual Stresses in Cylindrical Bar Under Combined Bending and Torsion, J. Manuf. Sci. Eng. 133(4) (2011) 044502.

https://doi.org/10.1115/1.4004496

[8] S. Mróz, A. Milenin, Numerical modelling of the metal flow and stock bending during the rolling of unequal angle bar, J. Materials Processing Technology, 177( 1-3) (2006) 561-565. https://doi.org/10.1016/j.jmatprotec.2006.04.027

[9] A.V. Bobylev, A.V. Kozlov, S.P. Maksimov, E.V. Khaliulin, Study of thermal phenomena during pipe bending with rolling, Vestnik of NMSTU, 16(3) (2018) 87-97. https://doi.org/10.18503/1995-2732-2018-16-3-87-97

[10] K.A. Mironov, A.V. Kozlov, V.G. Sherkunov, A.L. Suvorov, The study of power characteristics during pipe bending with burnishing, using an automated module and a PC, Vestnik of NMSTU, 50(2) (2015) 45-48.

[11]D.H. Norrie, G. de Vries, The Finite Element Method - Fundamentals and Applications, Academic Press, New York, 1973.

[12] R.R. Dema, R.N. Amirov, O.R. Latypov, Mathematical model for assessing the management of quality parameters of hot-rolled strips according to the criterion of local thickness variation, Materials Today: Proceedings. ICMTMTE 2019, (2019) 2417-2421. https://doi.org/10.1016/j.matpr.2019.08.047

[13] S.I. Platov, R.R. Dema, M.V. Kharchenko, R.N. Amirov, Experience of application of liquid lubricating materials during wide strip hot rolling, IOP Conference Series: Materials Science and Engineering, 287 (2018) 012011. https://doi.org/10.1088/1757-899X/287/1/012011

[14] R.R. Dema, V.V. Alontsev, O.B. Kalugina, A.N. Shapovalov, Computer simulation and research of the hot rolling process in Deform-3D, Materials Today: Proceedings. ICMTMTE 2019, (2019) 2312-2315. https://doi.org/10.1016/j.matpr.2019.07.677

[15] A.G. Vinogradov, O.S. Zhelezkov, K.Yu. Morozov et al., Investigation of the process of bending of ICR spring terminals using the finite element method, Processing of solid and layered materials, NMSTU, Magnitogorsk, (36) 2010 68-70.

[16] V.A. Arzamastseva, O.S. Zhelezkov, A.A. Laktyushin, Geometric parameters of the noncontact zone during double-support plastic bending of rod blanks, Theory and technology of metallurgical production, 32(1) (2020) 31-34. 